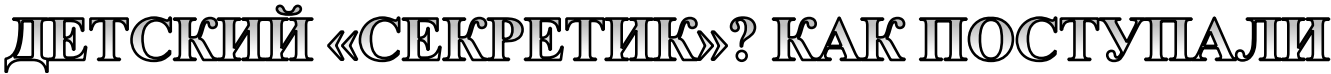

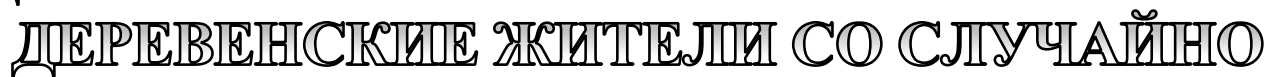

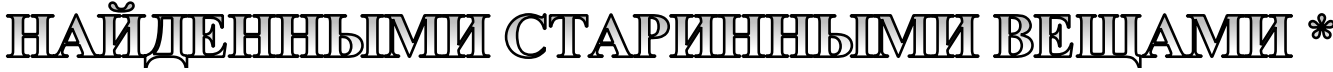

\section{Н.Б. Крыласова, Пермский федеральный исследовательский центр УрО РАН;}

Пермский государственный гуманитарно-педагогический университет

На месте средневекового Рождественского могильника, где осуществляются планомерные многолетние исследования, с XVII до середины XX вв. располагалась д. Постаногово. При строительстве и хозяйственной деятельности жители деревни находили в земле предметы из разрушенных погребений. По источникам известно, что в конце XIX в. эти вещи поступали в известную коллекцию Теплоуховых или продавались перекупщикам. Но какова была судьба находок в иные периоды, не известно. Открытие 2020 г. позволило отчасти узнать об этом. При раскопках обнаружена сравнительно небольшая яма, выложенная на дне галькой, в которой содержалось скопление средневековых вещей, вероятно, происходящих из одного женского погребения середины - второй половины XI в., вперемешку с предметами XIX в. Примерно посередине ямы сохранились следы забитого в землю колышка. На основании анализа данного объекта сделан вывод о том, что яма, вероятнее всего, появилась в результате детской игры.

Изучение специальной педагогической и психологической литературы показало, что в детской субкультуре, в особенности советского периода, были весьма популярны игры в «секретики» (у девочек) и тайники (у мальчиков), которые некоторыми авторами сопоставляются с известными в традиционной культуре формами ритуальных игровых похорон. Сравнение особенностей найденной ямы с описаниями указанных игр позволило сделать вывод, что яма могла являться мальчишеским тайником (кладом), отмеченным колышком, или «могилкой» с установленным на ней крестиком. То, что в яму наряду со средневековыми вещами попали вышедшие из употребления предметы XIX в., позволяет предполагать, что объект был сооружен в XX в.

Ключевые слова: археология, средневековый могильник, детская субкультура, «секретики», тайники, игровые похоронь, Пермский край.

В Карагайском районе Пермского края неподалеку от с. Рождественск, находится Рождественский языческий средневековый могильник, датируемый концом IX - нача- лом XII вв., на котором силами Камской археолого-этнографической экспедиции ПГГПУ и сотрудников Отдела истории археологии и этнографии ПФИЦ проводятся

\footnotetext{
* Работа выполнена в рамках государственного задания: номер государственной регистрации темы AAAA-A19-119032590066-2, при поддержке Министерства образования и науки Пермского края, соглашение № C-26/1192 от 19.12.2019 г.
} 
планомерные многолетние исследования. К настоящему времени на памятнике вскрыто 2200 м², изучено 401 погребение.

Могильник занимает один из мысов коренной террасы правого берега р. Обва в 300-500 м к востоку от Рождественского городища, которое являлось торговоремесленной факторией Волжской Булгарии и сопоставляется с известным по арабским письменным источникам городком Афкула [2, с. 499-506].

Погребения на могильнике располагались рядами, вытянутыми вдоль течения p. Обвы. Могильные ямы ориентированы по линии север-юг с незначительными отклонениями, преимущественно к северозападу. Судя по расположению остатков костяков и размещению погребального инвентаря, погребенные укладывались ногами к реке. Подавляющее большинство погребений сопровождалось инвентарем украшениями и деталями погребального костюма, различными орудиями, предметами вооружения, конского снаряжения, керамической и деревянной посудой.

За пределами многих погребений присутствовали жертвенно-поминальные объекты в виде округлых или овальных ямок диаметром 0,3-0,7 м, глубиной от 0,27 до 1,03 м от поверхности. Они имели ровное дно и вертикальные или наклонные стенки, либо чашевидную или конусовидную форму. Вокруг большинства таких ям находились столбовые ямки диаметром 4-7 см, вероятнее всего, оставшиеся от забитых в землю кольев, служивших основанием оградки или шалашика, защищавших принесенные предкам поминальные жертвы от животных и птиц. Эти ямы чаще всего располагались к северу или к югу от погребений, соответственно, «в изголовье» (51\%) или «в ногах» (40\%), занимая свободное пространство между рядами погребений. Иногда они тоже образуют ряды. По особенностям расположения и составу находок их нередко удается соотнести с конкретными погребениями. Преобладают ямы без инвентаря или с небольшим количеством находок, среди которых наиболее типичными можно считать зубы лошади, сосуд, удила, желтые стеклянные бусы, детали ременных наборов или поясных привесок [5, с. 51-65].

B XVII - первой половине XX вв. на месте могильника существовала деревня Постаногово. Срубные деревенские постройки существенного урона памятнику не нанесли, но углубленные в землю объекты - погреба и прочие хозяйственные ямы, столбовые ямы от заборов полностью или частично разрушили погребальные сооружения.

Безусловно, в процессе хозяйственной деятельности жители деревни регулярно находили предметы, происходящие из разрушенных погребений. В конце XIX в. находки с городища и могильника начал собирать А.Е. Теплоухов (1811-1885), главный управляющий Пермским нераздельным имением графов Строгановых, а позднее - его сын Ф.А. Теплоухов (1845-1905) - главный лесничий пермского нераздельного имения Строгановых. Значительную помощь в сборе находок и разнообразной информации об археологических памятниках оказывал служащий Рождественской волости Соликамского уезда К.Н. Чернов. Именно он в 1879 и 1880 гг. сообщил А.Е. Теплоухову о находках человеческих костяков и черепов - «чудских голов» - во время рытья ям и погребов в д. Постаногово.

Теплоуховы приложили немало усилий для того, чтобы жители деревень, непосредственно примыкавших к Рождественскому городищу, - Сивковой, Филипповой и Постаногово. Однако, не смотря на то, что крестьянам за их находки обязательно платили, они зачастую предпочитали сдавать найденные вещи не К.Н.Чернову, а местным дельцам, которые переправляли их в качестве лома на переплавку [2, с. 17-21]. К примеру, Н.Н. Новокрещенных оставил в своем отчете следующие сведения: «Наследники Хатинского теперь Полежаева - жиды, поселившиеся в Рождественском селе в виде управляющих смотрителей, скупают «найдушки» и отправляют для продажи в Нижний. 
Один из этих жидов говорил мне, что купил «найдушек» на 25 копеек, а передал в Нижний за 3 рубля» [13, с. 13].

Судя по сохранившимся сведениям, такая системная работа по сбору обнаруженных крестьянами археологических материалов была организована лишь в последние десятилетия XIX в., а что происходило с находками до этого и после - в советский период - остается неизвестным. Опрашивая жителей деревень во время археологических разведок о возможных находках, мы нередко сталкивались с ответом, что да, находили что-то, отдали детям играть...

В связи с этим весьма любопытным показался объект, обнаруженный на Рождественском могильнике в период полевого сезона 2020 года.

Этот объект, получивший условное наименование «яма 12/20», представлял собой овально-прямоугольную яму размерами 0,85 х 0,5 м, вытянутую по линии север-юг. Яма имела пологие стенки и неровное дно, максимальная глубина которого в центре ямы достигала 0,34 м от поверхности. Судя по профилю разреза ямы, примерно в центре ее был забит колышек диаметром $5 \mathrm{~cm}$, пространство вокруг которого засыпано слоем речного песка до 7 см (слой № 12). Над ямкой оставалось углубление, которое со временем заполнилось деревенским культурным слоем (слой № 2). При разборке ямы южнее и восточнее колышка на дне были расчищены сложенные двумя компактными кучками речные гальки (рис. 1).

В этой сравнительно небольшой ямке было обнаружено множество разнообразных предметов (43 экз.). Большинство из них концентрировались вокруг камней, уложенных на дне ямы, и под ними, за исключением трех предметов, сложенных в южной части ямы (рис. 1,2$)$.

Подавляющее большинство находок принадлежит к эпохе средневековья. Среди них представлены фрагменты серебряной височной подвески (рис. 3: 3, 25); 5 бронзовых бусин и бронзовая спиралевидная пронизка (рис. 3: 2, 8, 10, 19, 27);

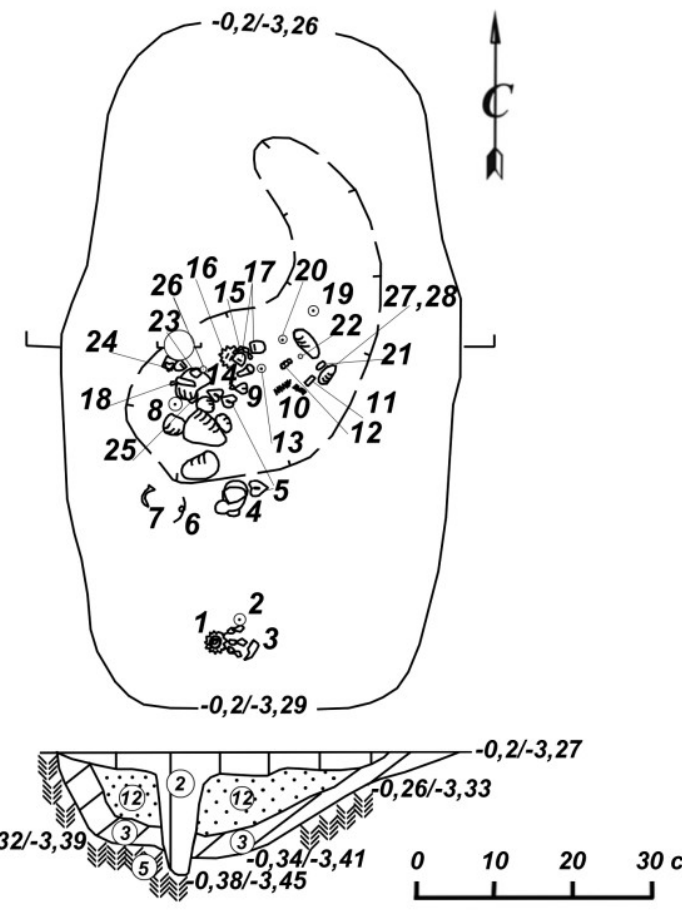

Рис. 1. План и профиль ямы 12/20.

Слои на профиле: 2 - плотный пестрочветный серо-коричневый суглинок-деревенский культурный слой; 3 - плотный бурый суглинок;

5 -материк - красная глина; 12 - светльй крупнозернистый песок (находки см. рис.3)

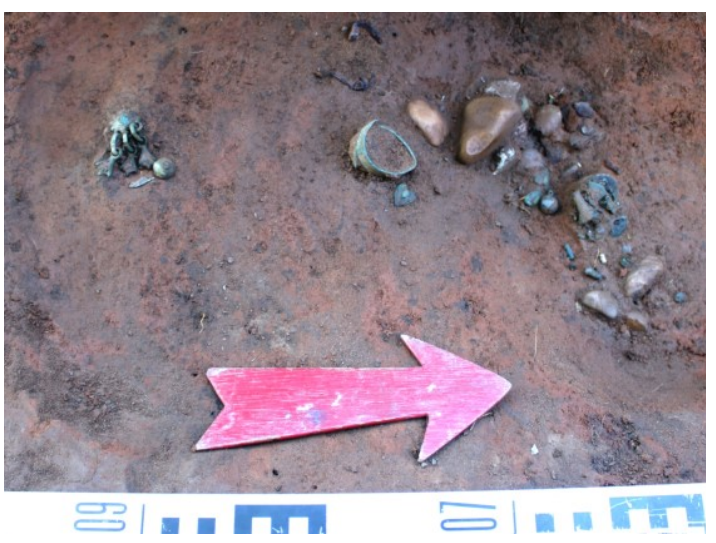

Рис. 2. Содержимое ямы 12/20 после расчистки. Вид с востока

фрагмент бронзовой привески в виде колокольчика (рис. 3: 11); 4 бусины и 4 экземпляра бисера из стеклянной пасты (рис. 3: 12, 13, 20, 22, 26; фрагменты бронзовой цепочки (рис. 3: 15); бронзовый крестопрорезной бубенчик (рис. 3: 9); бронзовая пронизка-колокольчик с сохранившимся внутри кожаным шнурком, к узлу на котором привязан еще один подобный бубенчик (рис. 3: 14); бронзовая шумящая 


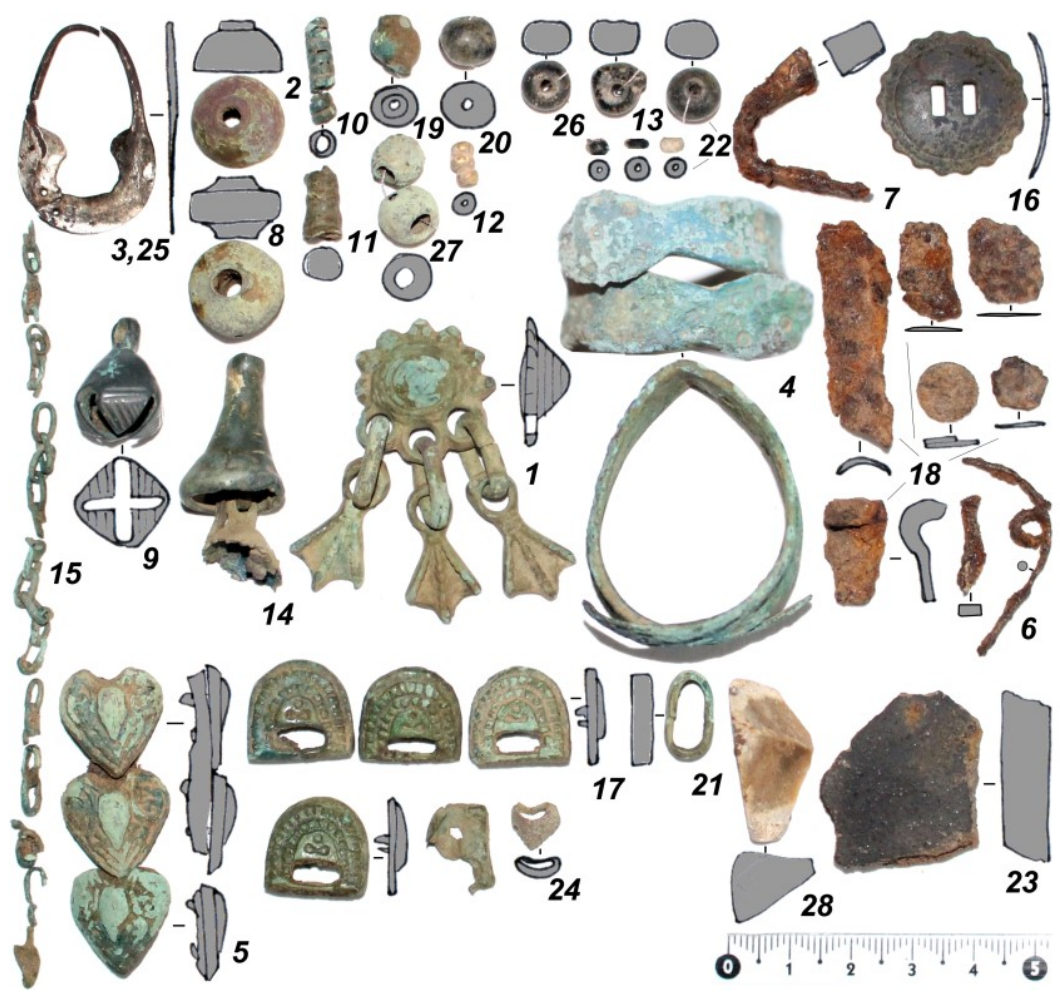

Рис. 3. Инвентарь ямы 12/20 (номера предметов по плану, рис.1): 1 - бронзовая шумящая умбоновидная подвеска; 2, 8, 19, 27 - бусы бронзовые; 3, 25- ррагменты серебряной височной подвески; 4- браслет бронзовый; 5, 17, 21, 24 -накладки поясные бронзовые;

6 - проволока железная; 7 - гвоздь подковный железный; 9 - бубенчик бронзовый;

10 - пронизка спиралевидная бронзовая; 11 - фр. бронзовой привески-колокольчика; 12, 13, 20 , 22, 26 - бусы и бисер стеклянные; 14 - бронзовая пронизка-колокольчик с кожаным шнурком и бронзовым бубенчиком внутри; 15 - фрагменты бронзовой цепочки; 16 - бронзовая бляхапуговица от конской сбруи; 18 -железные предметы; 23 - фрагмент деревенской керамики; 28 - кресальный кремень

умбоновидная подвеска (рис. 3: 1); бронзовый браслет (рис. 3: 4); 10 бронзовых поясных накладок (рис. 3: 5, 17, 21, 24); кресальный кремень (рис. 3:28). Представленный комплекс достаточно типичен для Рождественского могильника.

Височное украшение (рис. 3: 3, 25) принадлежит к типу калачевидных подвесок. Она изготовлена из серебряной проволоки, свернутой в овальное кольцо, нижний край которого был раскован и обрезан в форме калача. Подвеска была сломана на две части, найденные в разных местах ямы. Более крупный фрагмент (№ 25) располагался под камнем у колышка, а второй (№ 3) - в южной части ямы. Судя по тому, что на каждом из фрагментов возле места слома имеется по маленькому отверстию, подвеска, вероятно, была сломана еще в древности и подвержена ремонту. Подобные подвески получили широкое распространение в Пермском Предуралье в X - первой половине XII вв. [12, с. 38].

Среди бронзовых бусин небольшие цельнолитые (рис. 3: 19, 27) имели широкий хронологический диапазон бытования, как и спиралевидные пронизки (рис. 3: 10). Бусы-«флакончики» (рис. 3: 8) получили распространение в X - XI вв. [4, с. 265], в это же время в Прикамье широко использовались шаровидные бусины, состоящие из двух половинок (рис. 3: 2).

Обломок бронзовой привескиколокольчика (рис. 3: 11) принадлежит к типу колокольчиков с высокой цилиндрической шейкой, покрытой «поясками», которые появились в Пермском Предуралье во второй половине XI в. [7, с. 110 , рис. $1, a: 89,99]$.

Грушевидные бубенчики с крестовидной прорезью, нижняя часть которых покрыта косыми насечками (рис. 3: 9), в Нов- 
городе обнаружены в слоях от середины X до 1134 г. [14, с. 156 , рис.62/1-5; 8, с. 60]. Аналогична их датировка и в курганах Приладожья и Прионежья [4, с. 266, 277]. Но, судя по материалам Рождественского могильника, в Пермском Предуралье такие бубенчики сохранялись до конца XI в. [7, рис.1,a: 250].

Умбоновидные подвески (рис. 3: 1) можно считать характерным видом украшений для $\mathrm{X}-\mathrm{XI}$ вв. Судя по материалам Рождественского могильника, они применялись для украшения поясных сумочек и женской кожаной обуви [6, с. 15-18].

Пластинчатый бронзовый браслет с округлыми расширениями на концах, декорированный кружковым орнаментом (рис. 3: 4), датируется концом $\mathrm{X}$ - началом XII вв. [9, с. 49].

Судя по составу поясных накладок, они могли принадлежать к одному набору. Полуовальные накладки с прорезью внизу (рис. 3: 17, 24), которые использовались для декорирования основного ремня пояса, получили распространение со второй половины $\mathrm{X}$ в., но наиболее интенсивно использовались в первой половине XI в., зачастую в сочетании с квадратными или щитовидными накладками основного ремня и с привесками, характерными для поясных наборов XI в. Характерными элементами поясов конца X - XI вв. являлись накладки-обоймы в виде узкой прямоугольной пластины, загнутой вокруг ремня (рис. 3:21). Подсердцевидные накладки с выпуклым каплевидным выступом в центре, обрамленным растительными завитками (рис. 3: 5), являются характерным типом накладок, которые использовались в XI в. для оформления свисающего конца пояса (т.н. «Хвостовика»). Миниатюрные накладки-сердечки (рис. 3: 24) применялись в наборах поясных привесок.

В целом представленный комплекс средневековых находок можно отнести к середине - второй половине XI века. При этом данные вещи могли сочетаться в одном женском костюме и не исключено, что они происходят из одного разрушенно- го погребения. В процессе разборки ямы представлялось, что это мог быть не встречавшийся ранее вариант жертвенно-поминальной ямы. Выше уже приводились основные особенности таких ям. Данная яма отличалась, во-первых, подпрямоугольной формой, в то время как жертвенно-поминальные ямы обычно овальные или округлые, во-вторых - отсутствием столбовых ямок по периметру; в-третьих необычным заполнением; в-четвертых наличием большого количества вещей, тогда как в жертвенно-поминальные ямы обычно помещалось 1-2 предмета.

Однако в придонной части ямы под средневековыми находками была расчищена бронзовая сбруйная пуговица - c зубчатым краем и двумя прямоугольными прорезями (рис. 3: 16). Такими бляхамипуговицами обшивались ремни, седла и другие части упряжи. К сожалению, специалисты обошли вниманием такой элемент материальной культуры российского крестьянства, как украшения конской сбруи, и научных работ, посвященных данной тематике, обнаружить не удалось.

Однако сообщениями о подобных предметах пестрят сайты копателей, которые во множестве находят их в процессе своей незаконной деятельности, называя на своем копарьерском жаргоне «кониной». На основе их наблюдений, подобные украшения характерны для XIX в., они отливались в деревенских мастерских, а со второй половины XIX в. стали появляться штампованные предметы промышленного производства. K концу XIX - началу XX вв. такие украшения использовать перестали [3]. Поскольку данный предмет располагался в скоплении ниже средневековых вещей, нет сомнения, что он был помещен в яму одновременно с ними. Кроме него в яме обнаружены железные предметы - подковный гвоздь (рис. 3: 7), проволока (рис.3: 6), и неопределенные обломки (рис. 3: 18), а также фрагмент деревенской керамики (рис. 3: 23).

Таким образом, происхождение ямы, безусловно, связано с периодом функ- 
ционирования д. Постаногово. Когда это стало понятно, первая ассоциация, которая у нас возникла, была о детских «секретиках», в которые многим из нас приходилось играть.

Игре в «секретики», как яркому элементу детской субкультуры, посвящено множество работ специалистов педагогов и психологов. Но, пожалуй, наиболее детально ее характер разбирается в книге М.В. Осориной «Секретный мир детей в пространстве мира взрослых» [11].

М.В. Осорина отмечает, что детям свойственно находить на земле множество полезных вещей, обеспечивающих разнообразные детские нужды [11, с. 213]. Девочки смотрят на такие находки, как на предметы, с которыми можно что-то сделать, а мальчики более склонны их разрушить. Многие привлекательные предметы, подобранные детьми на улице, становятся содержимым девчоночьих «секретиков» и мальчишеских тайников [11, с. 219].

Характерными особенностями «секретиков» являются: маленькая неглубокая ямка, наличие фона (листья, фольга), на котором выкладываются интересные «штучки» - найденные предметы, головки цветов, разбитые цветные стеклышки и пр. Главной особенностью «секретика» является то, что он обязательно накрывается прозрачным стеклом - получается нечто вроде окошка в земле, через которое видна тщательно выложенная «красота». Стеклышко присыпается землей, которая при необходимости расчищается, чтобы полюбоваться самой или показать подружкам [11, с. 219-224].

Мальчики делают тайники. В отличие от «секретиков», они редко бывают в земле - чаще во всевозможных нишах, щелях, укрытиях, где можно сделать незаметное для других вместилище, куда закладываются разнообразные предметы, включая и найденные вещи. В тайниках мальчиков отсутствует эстетический аспект, им вообще порой не столь важно, что лежит в тайнике, сколь важно совершенство организации самого вместилища [11, с. 225-226].
С.Б. Адоньева проводит параллель между «секретиками», характерными, по ее мнению, исключительно для советского времени, и хорошо известными в традиционной культуре формами ритуальных игровых похорон [1, с. 216]. Она приводит описание игры в похороны начала XX века: «Летом дети часто роют ямочку в земле около наружных углов избы и играют в похороны. Это предвещает смерть кого-нибудь из членов того дома, около угла которого рыли дети ямочки...» [10] и аналогию в описании смысла «секретиков»: ««Секреты» нужно делать красивые и обязательно там, где их не могут найти, иначе будет горе - кто-то заболеет или кто-то умрет» [1, с. 217].

Из приведенных в статье описаний информантов можно сделать вывод, что хоронить могли не только умерших живых существ (птичек, лягушек, насекомых), но и неодушевленные предметы. При этом в описаниях обязательно упоминается сооружение гробика, крестика, проведение определенных ритуалов [1, с. 217]. В заключении С.Б. Адоньева, подчеркивает, что игра в «секретики», также как и похороны насекомых и птиц, могут быть в равной степени расценены как инсценировка или репетиция опыта смерти и с этой точки зрения обнаруживают общую семантику [1, с. 220].

Итак, как на основании этих исследований можно расценивать найденный при раскопках объект? С девичьим «секретиком» он явно не может связываться, так как, во-первых, представляет для этого слишком большую яму, а во-вторых, в нем отсутствует непременный элемент стекло, закрывающее разложенные в яме вещи. Ближе по смыслу - мальчишеский тайник или клад - тщательно обустроенная яма с выложенными на дне гальками, с заполнением из песка, специально откуда-то принесенного (в данном месте повсюду присутствует только глина), колышек, отмечающий место тайника. Но нельзя исключать и того, что данный объект являлся результатом детской игры в «похороны». Дети, закопавшие в яму 
находки, безусловно, знали, что они происходят из древней могилы (вспомним упомянутые выше сообщения о находках в деревне человеческих костяков и черепов). Попавшие в рассматриваемый комплекс отдельные деревенские предметы, вероятнее всего, тоже были найдены в земле, поэтому и отношение к ним было аналогичным. Учитывая сохраняющиеся по сей день представления о том, что ничего с кладбища брать нельзя, самым логичным было похоронить эти предметы. Яма, в которой были закопаны вещи, по форме напоминает могилу. А следы столбовой ямки могут быть связаны с основанием креста, установленного над ней.
Таким образом, обнаруженный на Рождественском могильнике объект демонстрирует один из вариантов того, как жители деревни поступали с найденными в разрушенных могилах вещами. Они вероятнее всего, как и везде, отдавали находки детям. А дети предпочли не играть с ними, а закопать в клад или даже провести ритуал похорон. Судя по тому, что вещи не были проданы в коллекцию Теплоуховых или перекупщикам, промышлявшим в конце XIX в., происхождение объекта может быть отнесено уже к XX в. Это подтверждается и наличием в комплексе вместе со средневековыми вещами предметов XIX в., которые уже вышли из употребления.

\section{Библиографический список}

1. Адоньева С.Б. Игра в «секретики» // СССР: Территория любви: Сб. статей. - М.: Новое издательство, 2008. - С. 208-223.

2. Белавин А.М., Крыласова Н.Б. Древняя Афкула: археологический комплекс у с. Рождественск. Пермь: ПФ ИИиА УрО РАН, 2008. - 603 с., ил.

3. Каталог деталей и украшений конской упряжи [Электронный ресурс] - URL: https://allkanina.ru/forum/viewtopic.php?f=2\&t=9 (дата обращения 11.09.2020)

4. Кочкуркина С.И. Памятники юго-восточного Приладожья и Прионежья. - Петрозаводск: Карелия, 1989. - 348 c.

5. Крыласова Н.Б. Исследование Рождественского могильника в Карагайском районе Пермского края: к вопросу о жертвенно-поминальных комплексах // Труды Камской археолого-этнографической экспедиции. - Пермь: ПГГПУ, 2016. - № 11. - С. 51-65.

6. Крыласова Н.Б. Особенности использования шумящих умбоновидных подвесок в костюме жителей Пермского Предуралья (по материалам Рождественского могильника) // Вестник Музея археологии и этнографии Пермского Предуралья. - Пермь: ПГГПУ, 2017. - № 7. - С. 15-18.

7. Крыласова Н.Б. Хронологические особенности материальной культуры Х-ХІ вв. (по материалам Рождественского могильника в Пермском крае) // Вестник Пермского университета. Вып.1(21). Пермь: ПГНИУ, 2013. - С.104-115

8. Лесман Ю.М. Хронология ювелирных изделий Новгорода (X-XIV вв.) // Материалы по археологии Новгорода / Новгор. археол. экспедиция МГУ, ИА АН СССР и Новгор. музея; [Под ред. В. Л. Янина, П. Г. Гайдукова]. - М. : Новгор. археол. экспедиция, 1990. - С.29-98

9. Моряхина К.В. Украшения рук Рождественского городища (по материалам раскопок 2008-2017 г.) // Вестник Музея археологии и этнографии Пермского Предуралья. - Пермь: ПГПУ, 2018. - № 8. C. $46-50$.

10. Несанелис Д.А., Шарапов В.Э. Тема смерти в детских играх: опыт этносемиотического анализа (по материалам традиционной культуры коми) // Смерть как феномен культуры: Межвуз. сб. науч. тр. Сыктывкарский гос. ун-т. - Сыктывкар: СГУ, 1994. - С. 122-134

11. Осорина М.В. Секретный мир детей в пространстве мира взрослых. СПб.: Прогресс книга, 2019. Серия: Психология. The Best. - 448 с.

12. Подосенова Ю.А. Калачевидные височные украшения на территории Пермского Предуралья в эпоху средневековья // Вестник Музея археологии и этнографии Пермского Предуралья. - Пермь: ПГГПУ, 2017. - № 7. -С. 38-44.

13. РА ИИМК РАН. Ф.1 1889 г. д. №29.

14. Седова М.В. Ювелирные изделия древнего Новгорода (X-XV вв.). - М.: Наука, 1981. - 196 с. 


\title{
A CHILD'S STASH? WHAT VILLAGERS USED TO DO WITH ACCIDENTAL ANTIQUE FINDS
}

\author{
N.B. Krylasova \\ Perm Federal Research Center UB RAS \\ Perm State Humanitarian Pedagogical University
}

From the XVII ${ }^{\text {th }}$ to the middle of the $\mathrm{XX}^{\text {th }}$ centuries the village of Postanogovo was located on the site of the medieval Rozhdestvensky burial ground where systemic long-term research has been carried out.

During construction and economic activities, the villagers used to find objects from destroyed burials in the ground. According to the sources it is known that at the end of the XIX century these things came to the well-known private Teploukhovs collection or were sold to dealers. The fate of the finds in other periods, however, is unknown.

During the excavations, a relatively small pit was discovered, laid out on the bottom with pebbles, which contained an accumulation of medieval items, probably originating from one female burial of the middle - second half of the $\mathrm{XI}^{\text {th }}$ century, mixed with items of the XIX ${ }^{\text {th }}$ century. In the middle of the pit there are traces of a peg driven into the ground. Based on the analysis of this object, it was concluded that the pit, most likely, appeared as a result of children's play.

The study of pedagogical and psychological literature showed that in the children's subculture, especially in the Soviet period, games of «secrets» (for girls) and hiding places (for boys) were very popular, which some authors compare with the forms of ritual play funerals known in traditional culture. Comparison of the features of the found pit with the descriptions of these games led us to conclusion that the pit could be a boy's cache (treasure) marked with a peg, or a «grave» with a cross on it. The fact that, along with medieval things, obsolete items of the XIX ${ }^{\text {th }}$ century fell into the pit, suggests that the object was built in the $\mathrm{XX}^{\text {th }}$ century.

Keywords: archaeology, medieval burial site, children's subculture, caches, stashes, makebelieve funerals, Perm Region.

\section{Сведения об авторе}

Крыласова Наталья Борисовна, доктор исторических наук, профессор, главный научный сотрудник, доцент, Пермский федеральный исследовательский центр УрО РАН (ПФИЦ УрО PAН), 614900, г. Пермь, ул. Ленина, 13А; Пермский гуманитарно-педагогический университет (ПГГПУ), 614990, г. Пермь, ул. Сибирская, 24; e-mail: n.krylasova@mail.ru 